\title{
Revascularization of the upper posterior circulation with the anterior temporal artery: an anatomical feasibility study
}

\author{
Ali Tayebi Meybodi, MD, ${ }^{1,2}$ Michael T. Lawton, MD, ${ }^{1,2}$ Dylan Griswold,, ${ }^{1,2}$ Pooneh Mokhtari, PhD, ${ }^{2}$ \\ Andre Payman, ${ }^{2}$ Halima Tabani, MD, ${ }^{1,2}$ Sonia Yousef, ${ }^{1,2}$ and Arnau Benet, MD ${ }^{1-3}$ \\ ${ }^{1}$ Department of Neurological Surgery, ${ }^{2}$ Skull Base and Cerebrovascular Laboratory, and ${ }^{3}$ Department of Otolaryngology-Head \\ and Neck Surgery, University of California, San Francisco, California
}

\begin{abstract}
OBJECTIVE In various disease processes, including unclippable aneurysms, a bypass to the upper posterior circulation (UPC) including the superior cerebellar artery (SCA) and posterior cerebral artery (PCA) may be needed. Various revascularization options exist, but the role of intracranial (IC) donors has not been scrutinized. The objective of this study was to evaluate the anatomical feasibility of utilizing the anterior temporal artery (ATA) for revascularization of the UPC.
\end{abstract}

METHODS ATA-SCA and ATA-PCA bypasses were performed on 14 cadaver specimens. After performing an orbitozygomatic craniotomy and opening the basal cisterns, the ATA was divided at the $\mathrm{M}_{3}-\mathrm{M}_{4}$ junction and mobilized to the crural cistern to complete an end-to-side bypass to the SCA and PCA. The length of the recipient artery between the anastomosis and origin was measured.

RESULTS Seventeen ATAs were found. Successful anastomosis was performed in 14 (82\%) of the ATAs. The anastomosis point on the PCA was $14.2 \mathrm{~mm}$ from its origin on the basilar artery. The SCA anastomosis point was $10.1 \mathrm{~mm}$ from its origin. Three ATAs did not reach the UPC region due to a common opercular origin with the middle temporal artery. The ATA-SCA bypass was also applied to the management of an incompletely coiled SCA aneurysm.

CONCLUSIONS The ATA is a promising IC donor for UPC revascularization. The ATA is exposed en route to the proximal SCA and PCA through the pterional-orbitozygomatic approach. Also, the end-to-side anastomosis provides an efficient and straightforward bypass without the need to harvest a graft or perform multiple or difficult anastomoses.

https://thejns.org/doi/abs/10.3171/2017.3.JNS162865

KEY WORDS cerebral revascularization; superior cerebellar artery; posterior cerebellar artery; basilar apex aneurysm; orbitozygomatic craniotomy; vascular insufficiency syndrome; vascular disorders; anatomy; oculomotor-tentorial triangle

$\mathrm{C}$ OMPLEX aneurysms involving the basilar apex, superior cerebellar artery (SCA), and posterior cerebral artery (PCA) may require bypass as part of their treatment strategy when dolichoectatic or fusiform morphology, dissecting etiology, or previous intervention makes them unclippable. . $4,16,20,21,24,26,31,37$ Patients with vertebrobasilar insufficiency may also benefit from flow augmentation to the upper posterior circulation (UPC) using a bypass to the PCA or SCA., $, 18,33,37$ UPC revascularization $^{3,14,16,18,20,21,24,26,27,31,33,37}$ can be performed using the superficial temporal artery (STA) in an STA-PCA or
STA-SCA bypass, and these more traditional extracranial (EC)-intracranial (IC) bypasses have been reported after trapping complex PCA or SCA aneurysms. $., 6,14,20,22,35$ The occipital artery has also been used for EC-IC revascularization of the PCA and SCA. ., $, 18,19,32,36$ The in situ SCAPCA bypass is another way to revascularize the distal UPC in rare cases in which the STA is unavailable or diminutive, ${ }^{23,24,26,30}$ but this bypass is technically challenging and has a steep learning curve. ${ }^{28}$ In our recently reported experience with the surgical treatment of dolichoectatic aneurysms of the basilar trunk, a bypass from the middle cere-

ABBREVIATIONS $A T A=$ anterior temporal artery; $E C=$ extracranial; $I C=$ intracranial; $M C A=$ middle cerebral artery; $P C A=$ posterior cerebral artery; $R A G=$ radial artery graft; SCA = superior cerebellar artery; STA = superficial temporal artery; UPC = upper posterior circulation.

SUBMITTED November 29, 2016. ACCEPTED March 6, 2017.

INCLUDE WHEN CITING Published online September 22, 2017; DOI: 10.3171/2017.3.JNS162865. 
bral artery (MCA) to the SCA with an interposition graft, in combination with distal clip occlusion of the aneurysm, showed promising results. ${ }^{21}$ These bypass choices that rely on scalp arteries or interposition grafts may not always be feasible. The STA or radial artery grafts (RAGs) may not be always available, ${ }^{24}$ and the saphenous vein graft may be too large in caliber to match the PCA or SCA. Occipital artery harvest during a frontotemporal-orbitozygomatic approach may be difficult due to patient positioning.

Novel IC-IC bypasses require anatomical research to find potential IC donor arteries and minimize the need for EC dissection for grafts and/or donors. We have previously reported our clinical experience using the anterior temporal artery (ATA) as an IC donor for low-flow bypass both to the anterior and posterior circulations. ${ }^{28}$ The ATA supplies a noneloquent region of the temporal lobe which, when the ATA is redirected in a bypass to a different territory, does not cause major permanent neurological sequelae after the ensuing infarction. ${ }^{12,13,23,28,29}$ Utilization of the ATA was first reported by Bederson and Spetzler to revascularize the MCA territory in a case of a giant unclippable MCA aneurysm, ${ }^{7}$ and we have also used the ATA in various bypasses to the MCA and SCA (Fig. 1)., ${ }^{1,28}$ However, reports on ATA utilization as a donor for IC-IC bypass to the UPC are scarce and do not provide relevant anatomical information regarding capacities and limitations. We were interested in the anatomical feasibility of utilizing the ATA as a donor for revascularization of the UPC and therefore assessed the feasibility of ATA-SCA and ATA-PCA bypass using surgical simulation in cadavers.

\section{Methods}

Seven cadaveric heads (14 hemispheres) were prepared for surgical simulation in the Skull Base and Cerebrovascular Laboratory at the University of California, San Francisco, using our customized formula. ${ }^{8}$ Each head was placed in a 3-pin clamp (Mizuho), with the vertex tilted approximately $15^{\circ}$ toward the floor and turned $45^{\circ}$ contralaterally, such that the malar eminence was the highest point of the simulated operative field. A large orbitozygo-
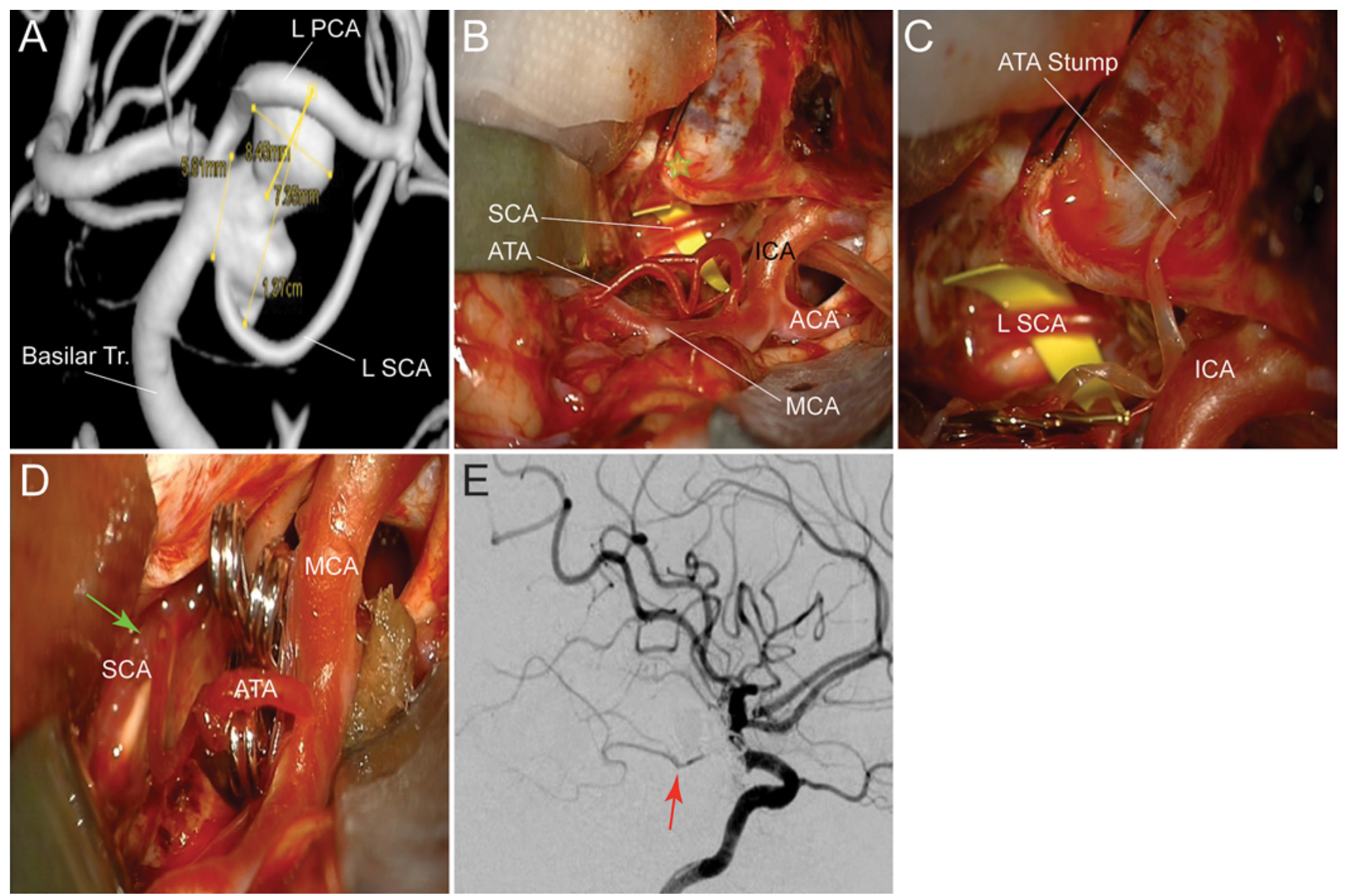

FIG. 1. A 55-year-old woman presented with subarachnoid hemorrhage from a multilobulated left (L) SCA aneurysm, seen on a rotational angiogram with $3 \mathrm{D}$ reconstruction $(\mathbf{A})$. She was referred for surgery to protect her from rehemorrhaging. The aneurysm could not be clipped without occluding the SCA and a bypass was needed. A prominent ATA was found in the sylvian fissure (B), and it had sufficient length to reach the SCA (C). The ATA was divided at the $\mathrm{M}_{3}-\mathrm{M}_{4}$ junction and transposed to the crural cistern, and an end-to-side anastomosis was completed with the SCA (D; arrow). After bypass patency was confirmed, the aneurysm neck was dissected and clipped. A postoperative angiogram (left ICA injection, lateral view) confirmed SCA reconstitution (E; arrow). Note the course of the SCA over the cerebellar vermis. The patient tolerated ATA sacrifice without neurological sequela. ACA = anterior cerebral artery; ICA = internal carotid artery; Tr. = trunk. Figure is available in color online only. 


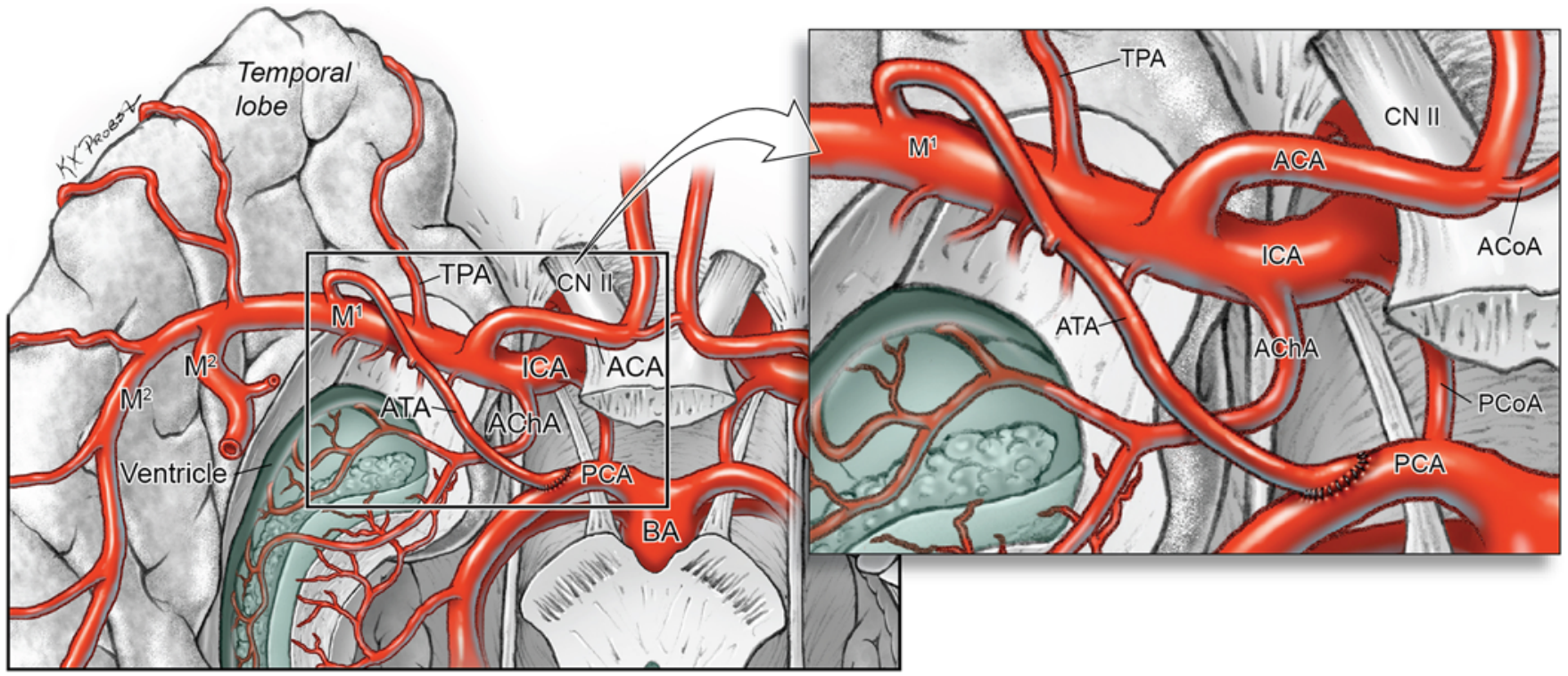

FIG. 2. Artist's illustration showing transposition of the ATA to reach the PCA. $A C h A=$ anterior choroidal artery; $A C o A=$ anterior communicating artery; $\mathrm{BA}=$ basilar artery; $\mathrm{CN}$ II = cranial nerve II; PCoA = posterior communicating artery; TPA = temporopolar artery. Copyright Arnau Benet. Published with permission. Figure is available in color online only.

matic craniotomy was completed. Following dural opening, the sylvian fissure was widely split, and the ATA was identified. The cisternal segment of the ATA was freed from arachnoid attachments and its small branches to the temporal lobe were cut. Next, the pretemporal corridor was obtained by retracting the temporal lobe laterally and posteriorly, which allowed access to the upper basilar area. The carotid, chiasmatic, crural, and ambient cisterns were opened to expose the basilar apex, the ipsilateral $\mathrm{P}_{1}$ and $\mathrm{P}_{2}$ segments of the PCA, and the SCA. Next, the ATA was divided at its opercular-cortical $\left(\mathrm{M}_{3}-\mathrm{M}_{4}\right)$ junction and mobilized posteriorly to reach the SCA and PCA region. The feasibility of completing an end-to-side anastomosis without undue tension on the donor artery was assessed for the most distal accessible point on the PCA and SCA. The anastomosis points on the SCA and PCA were reached though the corridor of the oculomotor-tentorial triangle, delimited by the oculomotor nerve medially and the tentorial edge laterally (Figs. 2 and 3; Video 1).

VIDEO 1. 3D clip demonstrating the ATA-PCA bypass in a cadaveric surgical simulation. Copyright Arnau Benet. Published with permission. Click here to view.

The diameter of the ATA stump and the diameters of the PCA and SCA at anastomosis points were recorded. The lengths of the PCA and SCA segments between their origin on the basilar artery (BA) and the anastomosis points were measured using a frameless stereotactic navigation system (Stryker). Also, the cisternal length of the ATA was recorded from its origin to the $\mathrm{M}_{3}-\mathrm{M}_{4}$ junction. The
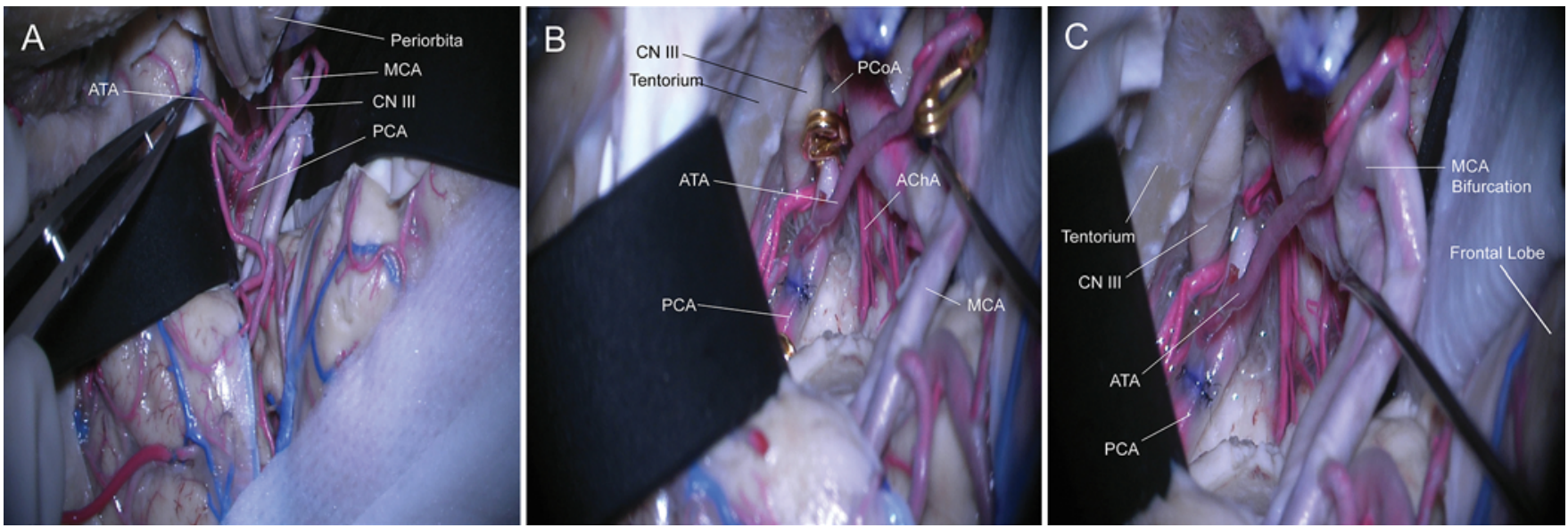

FIG. 3. Cadaveric simulation of the ATA-PCA bypass. A left orbitozygomatic approach is completed. A: The sylvian fissure is opened and the ATA is identified. B: The ATA is divided at the $\mathrm{M}_{3}-\mathrm{M}_{4}$ junction and mobilized toward the crural cistern lateral to the oculomotor nerve. The $\mathrm{P}_{2} \mathrm{PCA}$ is isolated between temporary clips, and an end-to-side anastomosis is completed between the ATA and PCA. C: Completed ATA-PCA bypass. Figure is available in color online only. 
branching map of the MCA was recorded to find possible correlations between specific branching patterns and the feasibility of bypass to the PCA and SCA.

\section{Results}

There were 17 ATAs in the 14 hemispheres assessed (3 had duplicate ATAs). ATA-P 2 PCA and ATA-SCA bypasses were feasible in 14 ATAs (82\%). All ATA-PCA and ATA-SCA bypasses were completed through the oculomotor-tentorial window using a pretemporal trajectory, without retracting the oculomotor nerve. Of the 14 ATA donors with a successful bypass, 9 (64\%) had a diameter greater than $1 \mathrm{~mm}$ (average $1.3 \mathrm{~mm}$ ). The diameters of the PCA and SCA at the anastomosis points were $2.7 \pm 0.4$ $\mathrm{mm}$ and $1.9 \pm 0.3 \mathrm{~mm}$, respectively. The ATA could be successfully anastomosed $14.2 \pm 4.8 \mathrm{~mm}$ from the PCA origin and $10.1 \pm 2.7 \mathrm{~mm}$ from the SCA origin. The mean cisternal length of the ATA in cases with successful bypass was $38.5 \mathrm{~mm}$, while the average cisternal length of the ATA in specimens in which bypass failed was 15.6 mm. All early-branching ATAs (i.e., ATAs originating prior to MCA bifurcation) were successfully mobilized to reach the UPC complex (Type I, $n=4$ ). From the non-early-branching ATAs (Type II, $\mathrm{n}=13$ ), 9 originated from the insular segment of the MCA (Type $\mathrm{II}_{\mathrm{A}}$ ), and 3 originated distally (on the opercular surface; Type $\mathrm{II}_{\mathrm{B}}$ ). Only Type $\mathrm{II}_{\mathrm{B}}$ ATAs did not have sufficient cisternal length to complete the bypass ( $n=3$; Fig. 4$)$.

\section{Discussion}

This study demonstrates that the ATA can be transposed to complete an end-to-side anastomosis to the UPC region in most cases (82\% of ATAs). Overall, in more than 50\% of all specimens, the ATA had enough cisternal length and more than $1 \mathrm{~mm}$ of distal diameter to allow bypass to the UPC (9/17). The results of the present work, as well as the provided clinical example (Fig. 1), validate the use of the ATA to augment flow in the UPC in selected cases.

Vascular lesions of the UPC can be accessed through 3 main approaches: 1) the frontotemporal-orbitozygomatic craniotomy for lesions from the basilar apex to the proximal $\mathrm{P}_{2 \mathrm{~A}}$ segment of the PCA and $\mathrm{s}_{1}$ segment of the SCA; 2) the subtemporal approach for distal $P_{2 A}$ and $P_{2 P}$ segments of the PCA, and $s_{2}$ segment of the SCA; and 3) posterior interhemispheric approaches to lesions of the $\mathrm{P}_{3}$ and $\mathrm{P}_{4}$ segments of the PCA and $\mathrm{s}_{4}$ segments of the SCA. ${ }^{10,18,25,34,37}$ Current evidence seems to weigh in favor of endovascular therapy for lesions of the distal PCA $\left(\mathrm{P}_{2}-\mathrm{P}_{4}\right)$, and bypass has not been shown to be of much benefit in these segments. ${ }^{9}$ In contrast, aneurysms of the proximal PCA and SCA are good candidates for surgical treatment. ${ }^{2,10,11,27}$ Of those lesions amenable to surgery, certain unclippable aneurysms may require bypass after aneurysm trapping, based on the pre- and/or intraoperative studies. ${ }^{15,17,20,21,26-28}$ Similarly, the surgical results with dolichoectatic aneurysms affecting the basilar trunk favor the use of MCA-PCA bypass. ${ }^{21}$ We have shown that the frontotemporal-orbitozygomatic approach provides excellent exposure of the proximal PCA and the SCA through the pretemporal corridor while minimizing temporal lobe retraction. ${ }^{37}$ Most lesions of the UPC requiring bypass can be addressed via a frontotemporal-orbitozygomatic approach, which includes ATA exposure during the wide splitting of the sylvian fissure. These factors combined show that the ATA (when of optimal diameter) can serve as a reliable IC donor to the UPC and therefore may eliminate the need for harvesting a graft vessel.

The ATA-PCA and ATA-SCA bypasses are performed in an end-to-side fashion, which is technically simpler than the side-to-side SCA-PCA bypass. ${ }^{24}$ Furthermore, the recipient arteries for posterior circulation bypasses are located in deeper corridors, which increases the technical difficulty of anastomosis and limits its clinical application. Therefore, the availability of the ATA as a donor is of great value when considering a bypass to the UPC. In addition, the overall anastomosis time for the ATA-SCA or ATA-PCA bypass may be less than the MCA-RAG-PCA bypass because it requires only 1 anastomosis in the former as opposed to 2 in the latter. These features make the ATA a promising donor in selected cases requiring bypass to the UPC.

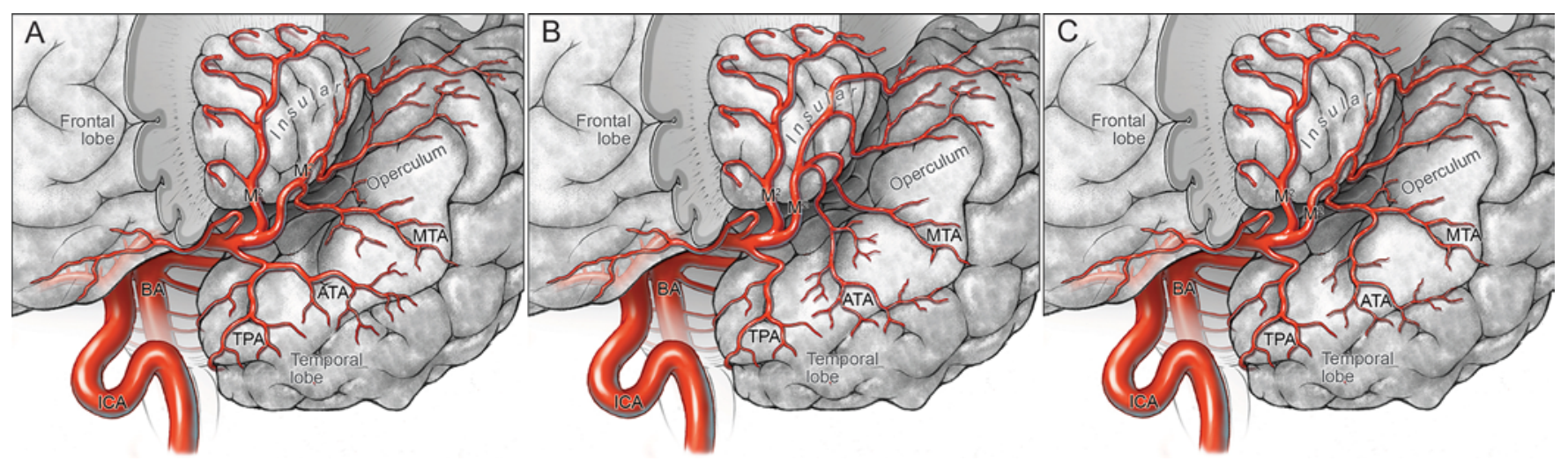

FIG. 4. Main branching patterns of the ATA and adjacent arteries regarding the feasibility of bypass to the PCA. A: Early-branching ATA (Type I), branching from the MCA prior to its bifurcation. B: Non-early-branching ATA originating from the insular segment of the MCA (Type $\left.\|_{A}\right)$. C: Non-early-branching ATA originating from the opercular segment of the MCA (Type $\left.I_{B}\right)$. All ATAs that failed a bypass to the PCA were Type $I_{B}$. MTA = middle temporal artery. Copyright Arnau Benet. Published with permission. Figure is available in color online only. 


\section{Clinical Evaluation of ATA-UPC Bypass Feasibility}

The branching pattern of the ATA determines the feasibility of bypass to the UPC. All ATAs studied had sufficient length to reach the UPC except 3 (18\%). In these specimens, the ATA origin was located distally on the opercular segment of a stem branch of the MCA (Fig. 4C). Such a branching pattern can be easily recognized in the preoperative angiogram to rule out the use of the ATA as a potential donor in those cases (Fig. 5). Moreover, the cisternal length of the ATA, the caliber match between the ATA and the recipient, and the length from the origin of the ATA to the plausible anastomosis point on the SCA or PCA can be measured on preoperative angiograms, allowing preoperative evaluation of the donor artery.

The present study reports the anatomical feasibility of the use of the ATA in IC-IC bypass procedures using surgical simulation in cadavers. This work builds on our clinical experience using the ATA as an intracranial donor for
UPC revascularization, as well as our greater experience with IC-IC bypasses. However, the present work includes a single clinical case illustration. Only further large-scale clinical applications will establish the impact of this bypass strategy and the role of the ATA in revascularizing the UPC. The clinical sequelae of ATA sacrifice have not been studied extensively, but anterior temporal lobectomy has shown that removal of the anterior temporal lobe (ATA territory) does not produce clinical deficits. ${ }^{12,13,23,28,29}$ Possible memory and cognitive deficits should be considered before using the ATA as a bypass donor, but these risks appear minimal.

\section{Conclusions}

This study demonstrates the anatomical feasibility of using the ATA in revascularization of the UPC. Based on our clinical application (ATA-SCA bypass) and the results
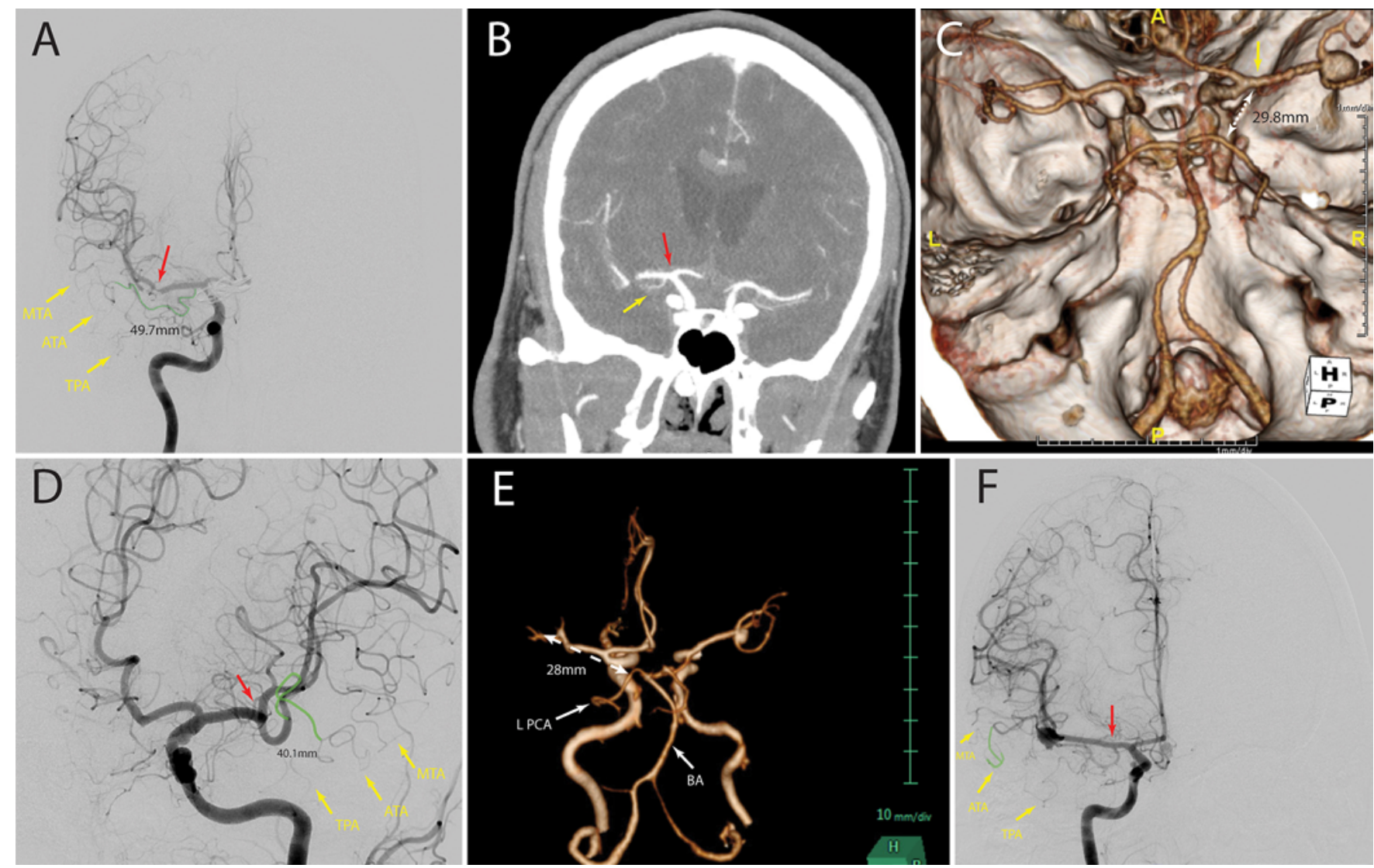

FIG. 5. Radiological illustration of the different branching patterns of the ATA relevant to the ATA-UPC bypass. Type I ATA in a patient with a previously clipped ACoA aneurysm (A-C). A: Anteroposterior digital subtraction angiogram showing a Type I ATA originating as an early MCA branch. Red arrow shows the MCA bifurcation point and the cisternal segment of the ATA is highlighted in green (length $=49.7 \mathrm{~mm}$ ). B: Coronal CT angiography depicting the MCA bifurcation (red arrow) and the origin of the ATA (yellow arrow). C: 3D reconstructed CT angiogram illustrating the required length of an ATA-PCA bypass $(29.8 \mathrm{~mm}$; dashed doublearrowed line). The distance is calculated from the ATA origin (yellow arrow) to the approximate $P_{1}-P_{2}$ junction. Type $I_{A}$ ATA (D and E). D: Left anterior oblique digital subtraction angiogram showing the Type $\|_{A} A T A$ originating from the insular $\left(M_{2}\right)$ segment of the MCA. Red arrow shows the MCA bifurcation point. The cisternal segment of this Type $\|_{A} A T A$ (from its origin to the $M_{3}-M_{4}$ junction) is marked in green with a length of $40.1 \mathrm{~mm}$. E: 3D reconstructed CT angiogram of the same patient depicting the required length of the ATA (from its origin at the $\mathrm{M}_{2} \mathrm{MCA}$ ) for an ATA-PCA bypass to the $\mathrm{P}_{1}-\mathrm{P}_{2}$ junction (28 mm). F: Anteroposterior digital subtraction angiogram showing a Type $\|_{B}$ ATA originating from the opercular segment of the MCA (highlighted in green; note the MCA bifurcation aneurysm in this patient). Although a common early MCA branch gives rise to the ATA (red arrow), TPA, and MTA, the ATA is originating from the opercular segment of this branch and cannot be mobilized. Figure is available in color online only. 
of this study, we propose that the ATA can be considered as a donor in bypasses to the SCA or PCA. The ATA expands the bypass armamentarium for neurosurgeons needing an alternative to traditional EC-IC and interpositional bypasses.

\section{Acknowledgments}

We would like to express our gratitude to the body donors and their families, who, through their altruism, contributed to this project. We also thank Ken Probst for the illustrations included in this article.

\section{References}

1. Abla AA, Lawton MT: Anterior cerebral artery bypass for complex aneurysms: an experience with intracranial-intracranial reconstruction and review of bypass options. J Neurosurg 120:1364-1377, 2014

2. Atalay B, Altinors N, Yilmaz C, Caner H, Ozger O: Fusiform aneurysm of the superior cerebellar artery: short review article. Acta Neurochir (Wien) 149:291-294, 2007

3. Ausman JI, Diaz FG, de los Reyes RA, Pak H, Patel S, Mehta B, et al: Posterior circulation revascularization. Superficial temporal artery to superior cerebellar artery anastomosis. J Neurosurg 56:766-776, 1982

4. Ausman JI, Diaz FG, Vacca DF, Sadasivan B: Superficial temporal and occipital artery bypass pedicles to superior, anterior inferior, and posterior inferior cerebellar arteries for vertebrobasilar insufficiency. J Neurosurg 72:554-558, 1990

5. Ausman JI, Lee MC, Chater N, Latchaw RE: Superficial temporal artery to superior cerebellar artery anastomosis for distal basilar artery stenosis. Surg Neurol 12:277-282, 1979

6. Avery M, Chehab S, Wong JH, Mitha AP: Intraoperative indocyanine green videoangiography to guide decision making regarding need for vessel bypass: A case report and technical note. Surg Neurol Int 7 (Suppl 2):S36-S39, 2016

7. Bederson JB, Spetzler RF: Anastomosis of the anterior temporal artery to a secondary trunk of the middle cerebral artery for treatment of a giant M1 segment aneurysm. Case report. J Neurosurg 76:863-866, 1992

8. Benet A, Rincon-Torroella J, Lawton MT, González Sánchez JJ: Novel embalming solution for neurosurgical simulation in cadavers. J Neurosurg 120:1229-1237, 2014

9. Chang SW, Abla AA, Kakarla UK, Sauvageau E, Dashti SR, Nakaji P, et al: Treatment of distal posterior cerebral artery aneurysms: a critical appraisal of the occipital artery-to-posterior cerebral artery bypass. Neurosurgery 67:16-26, 2010

10. Goehre F, Lehecka M, Jahromi BR, Lehto H, Kivisaari R, Hijazy F, et al: Subtemporal approach to posterior cerebral artery aneurysms. World Neurosurg 83:842-851, 2015

11. Honda M, Tsutsumi K, Yokoyama H, Yonekura M, Nagata I: Aneurysms of the posterior cerebral artery: retrospective review of surgical treatment. Neurol Med Chir (Tokyo) 44:164-169, 2004

12. Ipekdal HI, Karadas O, Erdogan E, Gokcil Z: Spectrum of surgical complications of temporal lobe epilepsy surgery: a single-center study. Turk Neurosurg 21:147-151, 2011

13. Jones JE, Blocher JB, Jackson DC: Life outcomes of anterior temporal lobectomy: serial long-term follow-up evaluations. Neurosurgery 73:1018-1025, 2013

14. Kalani MY, Hu YC, Spetzler RF: A double-barrel superficial temporal artery-to-superior cerebellar artery (STA-SCA) and STA-to-posterior cerebral artery (STA-PCA) bypass for revascularization of the basilar apex. J Clin Neurosci 20:887-889, 2013

15. Kalani MY, Ramey W, Albuquerque FC, McDougall CG, Nakaji P, Zabramski JM, et al: Revascularization and aneurysm surgery: techniques, indications, and outcomes in the endovascular era. Neurosurgery 74:482-498, 2014
16. Kalani MY, Spetzler RF: Internal carotid artery-to-posterior cerebral artery bypass for revascularization of the brainstem. J Clin Neurosci 24:151-154, 2016

17. Kalani MY, Zabramski JM, Hu YC, Spetzler RF: Extracranial-intracranial bypass and vessel occlusion for the treatment of unclippable giant middle cerebral artery aneurysms. Neurosurgery 72:428-436, 2013

18. Kazumata K, Yokoyama Y, Sugiyama T, Asaoka K: Occipital-posterior cerebral artery bypass via the occipital interhemispheric approach. Surg Neurol Int 4:90, 2013

19. Korinth MC, Thron A, Bertalanffy H, Gilsbach JM: Coil embolization of an incidental posterior cerebral artery aneurysm after initial OA-PCA bypass surgery. Zentralbl Neurochir 61:158-161, 2000

20. Lamis FC, De Paiva Neto MA, Cavalheiro S: Fusiform superior cerebellar artery aneurysm treated with STA-SCA bypass and trapping. Surg Neurol Int 5 (Suppl 4):S139-S142, 2014

21. Lawton MT, Abla AA, Rutledge WC, Benet A, Zador Z, Rayz $\mathrm{V}$, et al: Bypass surgery for the treatment of dolichoectatic basilar trunk aneurysms: a work in progress. Neurosurgery 79:83-99, 2016

22. Mizutani T, Kojima H, Asamoto S: Healing process for cerebral dissecting aneurysms presenting with subarachnoid hemorrhage. Neurosurgery 54:342-348, 2004

23. Quiñones-Hinojosa A, Lawton MT: In situ bypass in the management of complex intracranial aneurysms: technique application in 13 patients. Neurosurgery 57 (1 Suppl):140-145, 2005

24. Rodríguez-Hernández A, Huang C, Lawton MT: Superior cerebellar artery-posterior cerebral artery bypass: in situ bypass for posterior cerebral artery revascularization. J Neurosurg 118:1053-1057, 2013

25. Rodríguez-Hernández A, Rhoton AL Jr, Lawton MT: Segmental anatomy of cerebellar arteries: a proposed nomenclature. Laboratory investigation. J Neurosurg 115:387-397, 2011

26. Saito H, Ogasawara K, Kubo Y, Tomitsuka N, Ogawa A: Treatment of ruptured fusiform aneurysm in the posterior cerebral artery with posterior cerebral artery-superior cerebellar artery anastomosis combined with parent artery occlusion: case report. Surg Neurol 65:621-624, 2006

27. Sanai N, Tarapore P, Lee AC, Lawton MT: The current role of microsurgery for posterior circulation aneurysms: a selective approach in the endovascular era. Neurosurgery 62:1236-1253, 2008

28. Sanai N, Zador Z, Lawton MT: Bypass surgery for complex brain aneurysms: an assessment of intracranial-intracranial bypass. Neurosurgery 65:670-683, 2009

29. Sindou M, Guenot M, Isnard J, Ryvlin P, Fischer C, Mauguière F: Temporo-mesial epilepsy surgery: outcome and complications in 100 consecutive adult patients. Acta Neurochir (Wien) 148:39-45, 2006

30. Sundt TM Jr, Campbell JK, Houser OW: Transpositions and anastomoses between the posterior cerebral and superior cerebellar arteries. Report of two cases. J Neurosurg 55:967970,1981

31. Taqi MA, Lazzaro MA, Pandya DJ, Badruddin A, Zaidat OO: Dissecting aneurysms of posterior cerebral artery: clinical presentation, angiographic findings, treatment, and outcome. Front Neurol 2:38, 2011

32. Touho H, Karasawa J, Ohnishi H, Kobitsu K: Anastomosis of occipital artery to posterior cerebral artery with interposition of superficial temporal artery using occipital interhemispheric transtentorial approach: case report. Surg Neurol 44:245-250, 1995

33. Tulleken CA, Streefkerk HJ, van der Zwan A: Construction of a new posterior communicating artery in a patient with poor posterior fossa circulation: technical case report. Neurosurgery 50:415-420, 2002 
34. Turner JD, Spetzler RF: Surgical approaches to arteriovenous malformations near the posterior incisura. World Neurosurg 82:314-315, 2014

35. Ulku CH, Cicekcibasi AE, Cengiz SL, Ustun ME, Buyukmumcu M: Proximal STA to proximal PCA bypass using a radial artery graft by posterior oblique transzygomatic subtemporal approach. Neurosurg Rev 32:95-99, 2009

36. Vishteh AG, Smith KA, McDougall CG, Spetzler RF: Distal posterior cerebral artery revascularization in multimodality management of complex peripheral posterior cerebral artery aneurysms: technical case report. Neurosurgery 43:166-170, 1998

37. Zador Z, Lu DC, Arnold CM, Lawton MT: Deep bypasses to the distal posterior circulation: anatomical and clinical comparison of pretemporal and subtemporal approaches. Neurosurgery 66:92-101, 2010

\section{Disclosures}

Dr. Tayebi's research fellowship at the University of California, San Francisco, is supported by Medtronic.

\section{Author Contributions}

Conception and design: Benet, Tayebi Meybodi, Lawton. Acquisi- tion of data: Tayebi Meybodi, Griswold, Mokhtari, Payman. Analysis and interpretation of data: Tayebi Meybodi, Griswold. Drafting the article: Tayebi Meybodi. Critically revising the article: all authors. Reviewed submitted version of manuscript: Benet, Tayebi Meybodi, Lawton, Mokhtari, Payman, Tabani, Yousef. Approved the final version of the manuscript on behalf of all authors: Benet. Statistical analysis: Griswold. Administrative/technical/material support: Benet. Study supervision: Benet.

\section{Supplemental Information}

Videos

Video 1. https://vimeo.com/216012464.

\section{Current Affiliations}

Drs. Tayebi Meybodi and Lawton: Department of Neurological Surgery, Barrow Neurological Institute, Phoenix, Arizona.

\section{Correspondence}

Arnau Benet, Department of Neurosurgery, Barrow Neurological Institute, Phoenix, AZ, 350 W Thomas Road, Phoenix, AZ 85103. email: arnaubenet@gmail.com. 